- - - - - - مجلة علوم الرافني، المجلد 24، العدد 4، ص35 -46، 2013 - - - - -

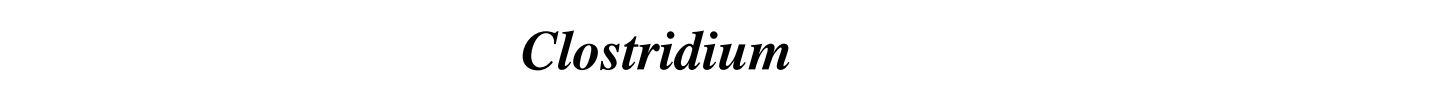 قالبليتها عل إنتاج الكحط الاثيلي من أنواع مختلفة من النشب النشب
}

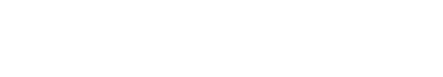

$$
\begin{aligned}
& \text { قبم علوم الحية } \\
& \text { كلية العلوم } \\
& \text { جلمعة الموصل }
\end{aligned}
$$

Email: ausama1962@yahoo.com

$$
\text { (تاريخ الاستلام 16/ } 10 \text { / } 2012 \text { ؛ تاريخ القبول } 18 \text { / } 2 \text { / } 2013 \text { ) }
$$

\section{المالغص}

مُ في هذه الدرلسة عزل وتشخيص نوعين من البكتريا المحللة للسليلوز ولأشببه للسليلوز وهي Clostridium cellulolyticum Clostridium cellulovorans الحصول عليه من منلطق مختلفة من مدينة الموصل. لظٔهرت الدرلسة أن لبكتريا C. cellulovorans القدرة على تخمير غشب الزيلة الزان وإنتاج الكحول خلل

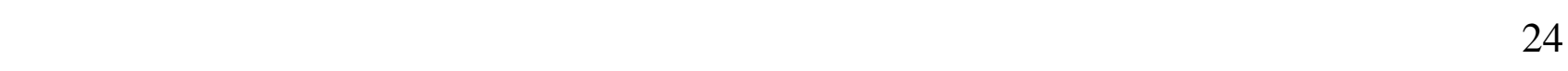

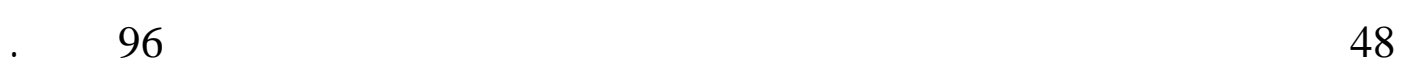

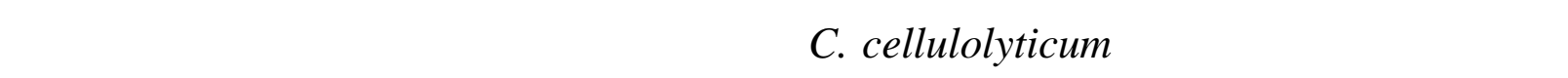

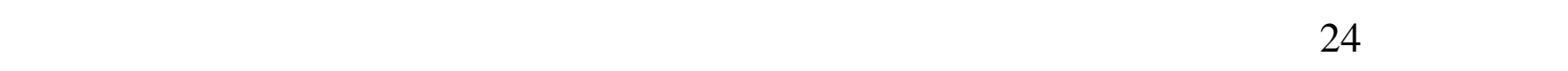
بعد 48ساعة من التحضن.

الكاملت الدالة: Clostridium، وأثببه للسليلوز، غثب الزان، الكحول، التنوب. 


\title{
Isolation and Identification of some Clostridium spp. from Decaying Wood and Study of their Ability to Produce Ethanol from Different Kinds of Wood
}

\author{
Ausama M. Al-Naemee \\ Department of Biology \\ College of Science \\ University of Mosul
}

\begin{abstract}
In this study we isolated and identified two species of bacteria degrading cellulose and semicellulose; C. cellulovorans and C. cellulolyticum of decaying wood samples, which were obtained from different parts of Mosul city.

The study showed that $C$. cellulovorans had the ability to ferment Lithocarpus sp.and produce ethanol within 24 hours from the start of incubation, and came in second place each of Santalum sp., Betula sp. and Eucalyptus sp. within 48 hours and finally came Pinus sp., Quercus sp., Populus sp. and Spruce sp. within 96 hours.

The study also demonstrated that the bacteria C. cellulolyticum produced ethanol from Lithocarpus sp., Santalum sp., Betula sp. and Spruce sp. within 24 hours of incubation and came in second place Pinus sp., Quercus sp., Populus sp. and Eucalyptus sp. after 48 hours of incubation.
\end{abstract}

\section{المقمة}

تعد بكتريا Clostridium cellulovorans من الأنواع اللاهوائية النمو وللسالبة لصبغة كره وهي عصوية للثكل غير متحركة والمكونة للابواغ، وتكون الأبواغ مركزية أو تحت نهائية الموقع ولها قدرة على تحليل للسليلوز في الأوسط الزرعية الحاويه عليه خلل (48)ساعة عبر إنتلجها لأذزيم cellulase الخارج خلوي وهذا الاذزيم يتكون من بروتينت مختلفة تسم cellulosome ( Cavedonk and Canale,1990 ; Shoseyovo et al., 1990; Wood and Scorr,1988; Sleat et .(al.,1984

كما تمتاز هذه البكتريا بقدرتها على تحليل البكتين pectin ولثشبه للسليلوزت وتخمير الزاليلان xylan سلوبايوز cellobios كلوكوز glucose، مالتوز maltose، كالاكتوز sucrose ،سكروز ،لكتوز و lactose Doi and Kosugi, 2004; Sung et al., 2004; Doi et ) acetate والخليك butyrate البيوتريت .(al.,1998 
وقد توجهت أظار البلحثين للاستخدمها ضمنطررائق القنية الاحيائية لتحويل المكونت النباتية للسليلوزية

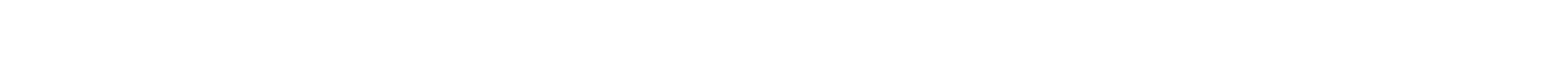
اللسليلوزية لتحليلها ( Fierobe et al., 2002; Koichiro et al., 2002 ; Boisset et al., 1998 ). وهنك أنواع بكتيرية عدية لها القدرة على تحليل اللسليلوز من بينها بكتريا Clostridium cellulolyticum

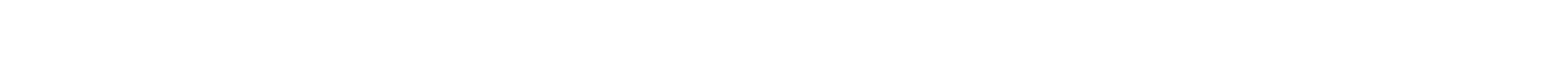

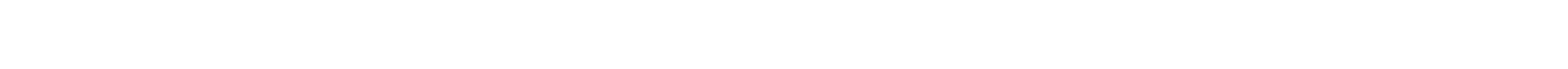

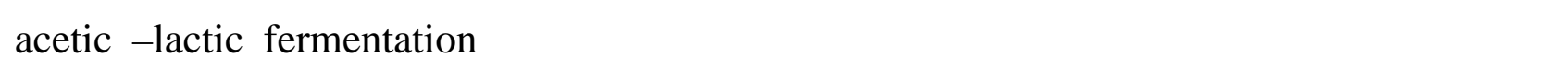

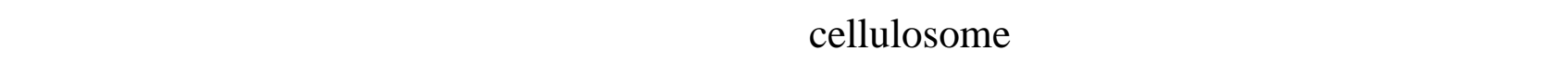

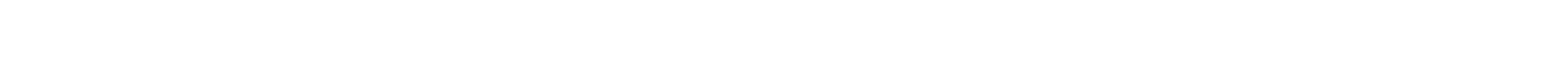
تضم كل من الزايلوز، الارابينوز، الفركتوز، الكالاكتوز، المانوز والرايبوز ( Giallo et al.,1983; Gowen (et al., 2010; Wendy et al., 2011 من المظفات البيئية ذات القدرة على النتاج الوقود الحيوي الايثانول الذي زاد الاهتملم في تخليقه بالطرقي الاحيائية مع ليجاد البكتريا الملائمة في إنتلجه (Desvaux et al., 2001)

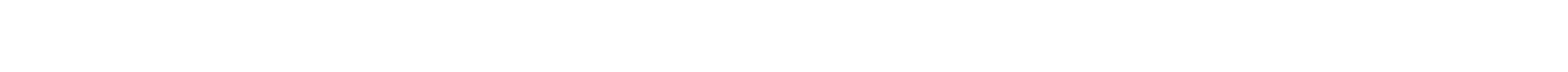
والخمائر وتحللها بلستخدلم الززيماتها الخارجية، والخشب مادة عضوية مسلمية لها القدرة على المتصاص

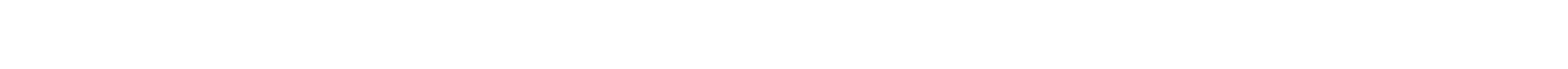

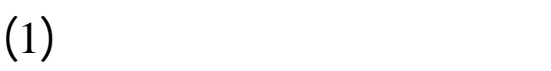

\section{الجطر 1:مكونت الهثب لانولع مختلفةمن النبلتا}

\begin{tabular}{|c|c|c|c|}
\hline الاكنين \% & الشباd للسليلوز\%\% & السليلوز\%\% & نوع الهشب \\
\hline 19.7 & 48.9 & 31.4 & 1 - Pinus sp. - 1 \\
\hline 14.9 & 52 & 33.1 & 2 - زلن Lithocarpus sp \\
\hline 19.2 & 47.5 & 33.3 & Quercus sp. بلوط \\
\hline 15.4 & 50.3 & 34.3 & Santalum sp. 4 - صندل \\
\hline 16.7 & 49.3 & 34 & 5 - جوز Populus sp \\
\hline 14.9 & 51.8 & 33.3 & 6 - بندق . Betula sp \\
\hline 15.4 & 50.3 & 34.3 & 7 - يوكالبتوس . Eucalyptus sp \\
\hline 27.7 & 31.6 & 40.7 & 8 - تنوب Spruce sp. \\
\hline
\end{tabular}

(Diaz-vaz et al., 2009 ; Klemn et al., 2005 ; Roger, 1984 ; Vian et al., 1983) 


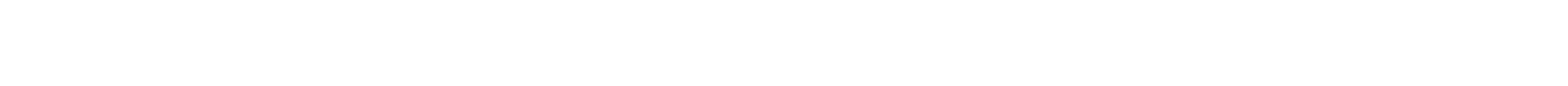

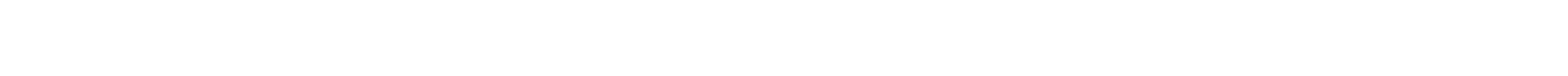

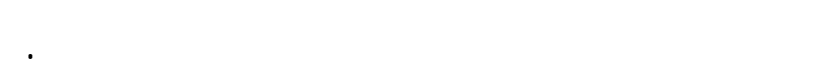

\section{المواد وطرائق الهلى}

\section{1 جمع العينت:}

جمعت عينات من قطع الأغشب المتحللة من مطقة غابلت مدينة الموصل قرب نهر نجلة ومن

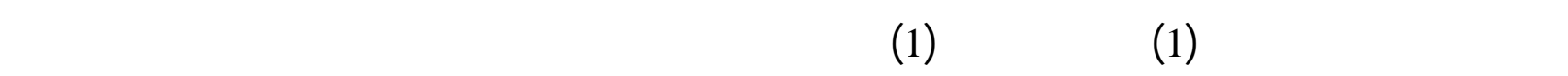

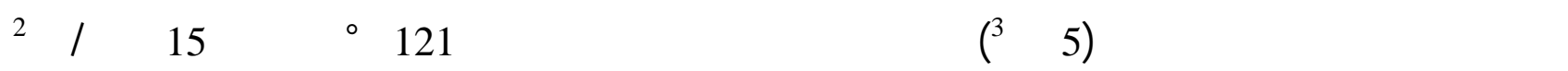
لمة 15 دقيقة.
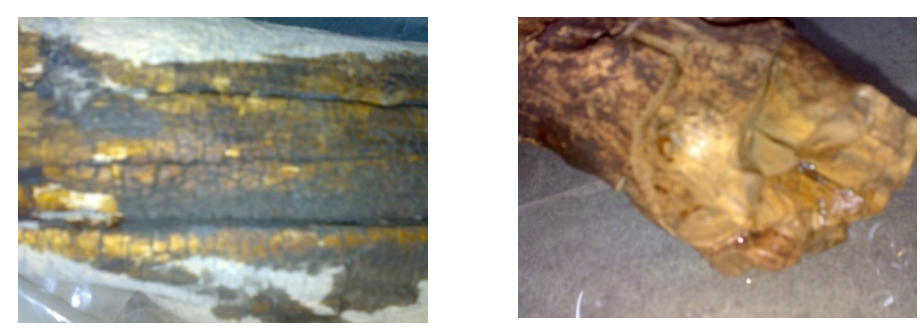

\section{الصورة 1: عينت من الغشب المتطل}

2 - 2 2

لخذ حملت لوب من أنابيب المرق المغذي المزروعة من عينت قطع الأنشلب المتحللة المذكورة في الفقرة (1) وزرعت عميقا في الأوسط الزبل الفرعية الصلبة التالية: أ - وسط ( أ ) Clostridium cellulovorans medium ويتكون من المواد التالية:

$\begin{array}{rr}\mathrm{K}_{2} \mathrm{HPO}_{4} \times 3 \mathrm{H}_{2} \mathrm{O} & 1.00 \mathrm{~g} \\ \mathrm{NH}_{4} \mathrm{Cl} & 1.00 \mathrm{~g} \\ \mathrm{KCl} & 0.50 \mathrm{~g} \\ \mathrm{MgSO}_{4} \times 7 \mathrm{H}_{2} \mathrm{O} & 0.50 \mathrm{~g} \\ \text { Cysteine- } \mathrm{HCl} \times \mathrm{H}_{2} \mathrm{O} & 0.15 \mathrm{~g} \\ \text { Trypticase peptone } & 0.50 \mathrm{~g} \\ \text { Yeast extract } & 0.50 \mathrm{~g} \\ \text { Cellobiose } & 5.00 \mathrm{~g} \\ \mathrm{Na}_{2} \mathrm{CO}_{3} & 1.00 \mathrm{~g} \\ \mathrm{Na}_{2} \mathrm{~S} \times 9 \mathrm{H}_{2} \mathrm{O} & 0.15 \mathrm{~g} \\ \text { Trace element solution* } & 1.00 \mathrm{ml}\end{array}$




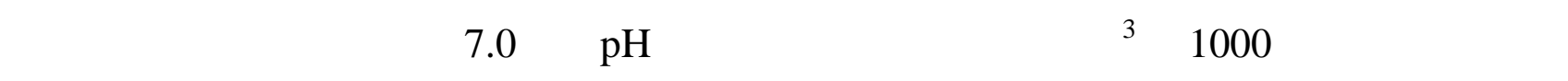

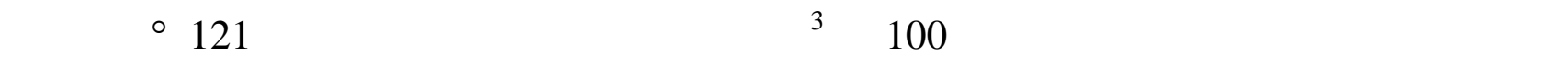
15باوند/انجج² لمدة 15 دقيقة. حضر محلول المعان الضئيلة Trace element solution* كما موضخح أننا

$$
\begin{array}{rr}
\mathrm{HCl}(25 \% ; 7.7 \mathrm{M}) & 10.00 \mathrm{ml} \\
\mathrm{FeCl}_{2} \times 4 \mathrm{H}_{2} \mathrm{O} & 1.50 \mathrm{~g} \\
\mathrm{ZnCl}_{2} & 70.00 \mathrm{mg} \\
\mathrm{MnCl}_{2} \times 4 \mathrm{H}_{2} \mathrm{O} & 100.00 \mathrm{mg} \\
\mathrm{H}_{3} \mathrm{BO}_{3} & 6.00 \mathrm{mg} \\
\mathrm{CoCl}_{2} \times 6 \mathrm{H}_{2} \mathrm{O} & 190.00 \mathrm{mg} \\
\mathrm{CuCl}_{2} \times 2 \mathrm{H}_{2} \mathrm{O} & 2.00 \mathrm{mg} \\
\mathrm{NiCl}_{2} \times 6 \mathrm{H}_{2} \mathrm{O} & 24.00 \mathrm{mg} \\
\mathrm{Na}_{2} \mathrm{MoO}_{4} \times 2 \mathrm{H}_{2} \mathrm{O} & 36.00 \mathrm{mg} \\
\text { Distilled water } & 990.00 \mathrm{ml}
\end{array}
$$

ب - ويط (ب) Clostridium cellulolyticum medium ويتكون من المواد التالية:

$$
\begin{array}{rr}
\left(\mathrm{NH}_{4}\right) 2 \mathrm{SO}_{4} & 1.300 \mathrm{~g} \\
\mathrm{KH}_{2} \mathrm{PO}_{4} & 1.500 \mathrm{~g} \\
\mathrm{~K}_{2} \mathrm{HPO}_{4} \times 3 \mathrm{H}_{2} \mathrm{O} & 2.900 \mathrm{~g} \\
\mathrm{MgCl}_{2} \times 6 \mathrm{H}_{2} \mathrm{O} & 0.200 \mathrm{~g} \\
\mathrm{CaCl}_{2} \times 2 \mathrm{H}_{2} \mathrm{O} & 0.075 \mathrm{~g} \\
\mathrm{FeSO}_{4} \times 7 \mathrm{H} 2 \mathrm{O} & 1.250 \mathrm{mg} \\
\text { Yeast extract } & 2.000 \mathrm{~g} \\
\text { Cellobiose } & 6.000 \mathrm{~g} \\
\text { Cysteine-HCl x H} \mathrm{H} & 0.500 \mathrm{~g} \\
\text { Trace element solution } & 1.00 \mathrm{ml}
\end{array}
$$

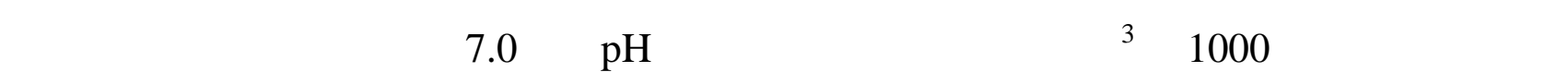

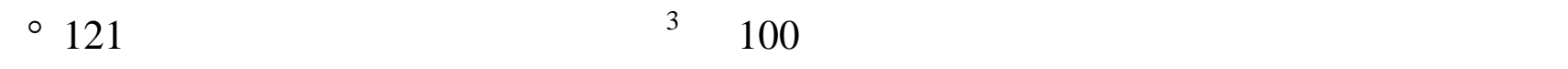
وضغط 15 باوند/انجج² لمدة 15 دقيقة.

حضر محلول المعان الضئيلة Trace element solution كما موضح في الفقرة اللسابقة (أ). (Hungate,1969)

Clostridium الأوسط الزرعية المستخمة في الاختبارات الكيميلحيوية لتثخيص بكتريا : Clostridium cellulolyticum و وبكتريا cellulovorans

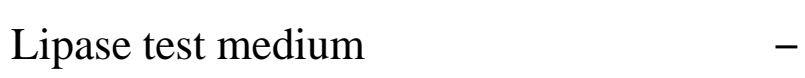

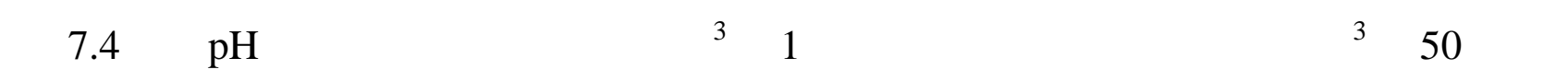

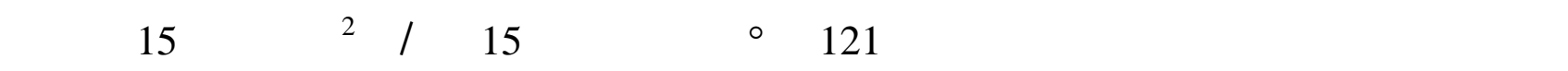
.(Prescott et al.,1996) 
Gelatin liquefaction test medium وسط لختبار تمبع الجيلاتين -

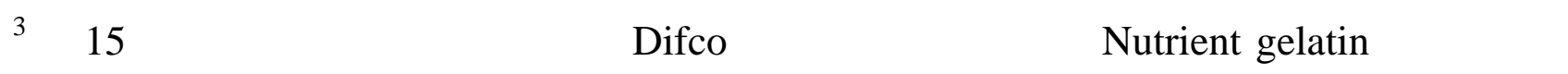
وعتم بالموصة وعلى درجة 121 م مضغط 15 باوند/انج2² لمدة 15 رقيقة. Stormy fermentation test medium وسط لختبار التخمر العاصف عاونة

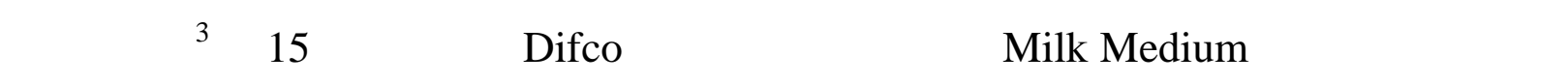
لختبار مم كثم بالموصدة على درجة 121 مم وضغط 15 باوند/انجج² لمدة 15 دقيقة. Carbohydrate fermentation medium وضط تخمر الكاربوهيدرات حضر 950سم 30 ونط الكثف عن تخمر الكاربوهيدرات والمكون من وسط ماء البتون المكون من ما كلوريد الصونيون

لكمل الحجم إلى لترماء مقطر ومعتم وضبطت قيمة الـ ـ pH على 7.5 وعثم الوسط بالموصة على درجة

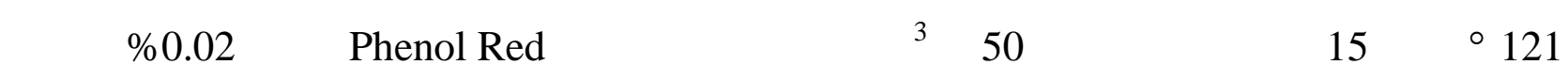

$$
\begin{aligned}
& \text { حضر كما يلي : } \\
& \text { هيدروكسيد الصوديوم عيارية } 0.01 \text { م } \\
& \text { صبغة الفينول الاحمر }
\end{aligned}
$$

لكمل الحجم إلى 250سم 3ماء متطر، فحصلنا على تركيز الدلل 0.04\%، ثم اضيف حبم مساو من الماء

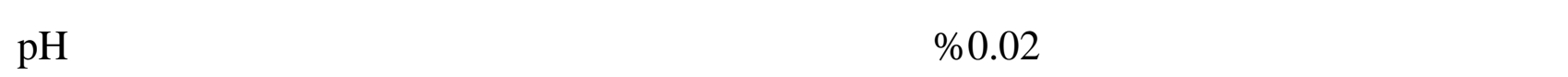

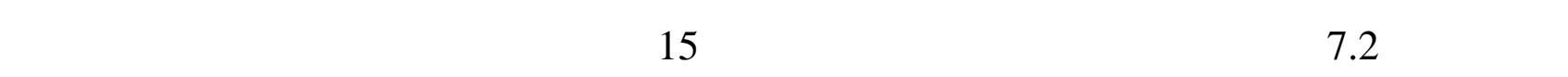

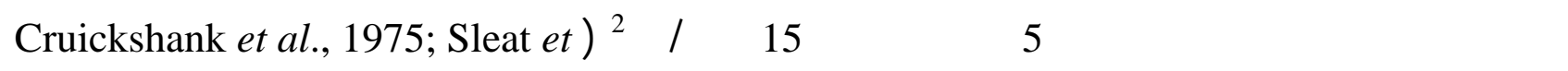
.(al., 1984

3 - تحضير مستخلصل الأنشلب النبلتية:

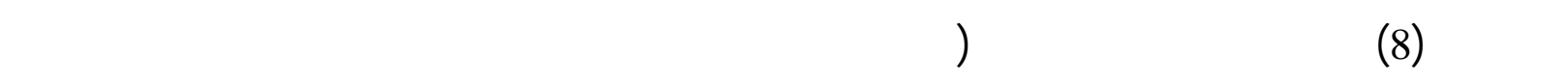

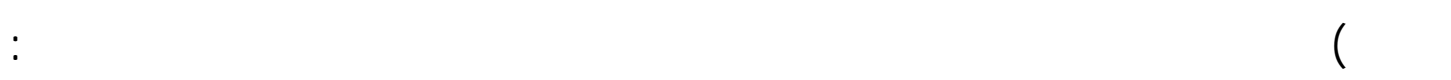

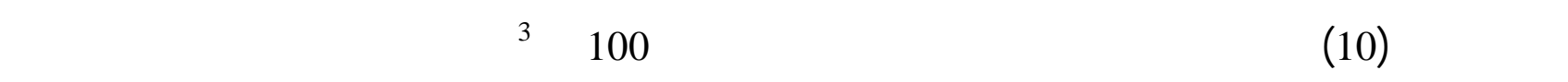
نوع Philips وششح المحلول ولخذ الرلشح ووضع في حاوية زجلجية معقمة. 
جمعت الحاويت المقمة والمحتوية على مستخلصت النباتلت للساقة النكر ووضعت بالتجميد (4 - ثم) ثم

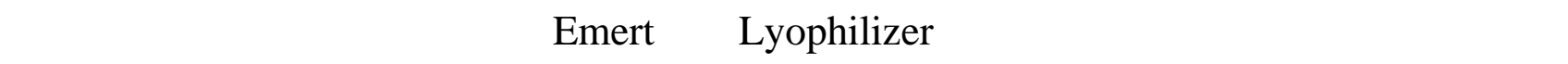
من النباتلت المنكورةسابقاً (للسطان، 1993).

\section{4 - أختبار نمو البكتربا المحالة للأذشبل: الميلب:}

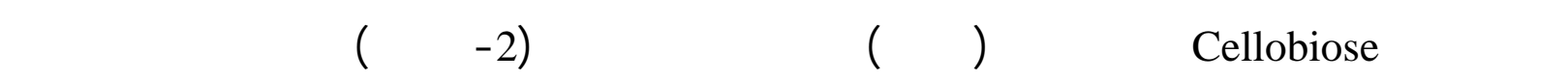

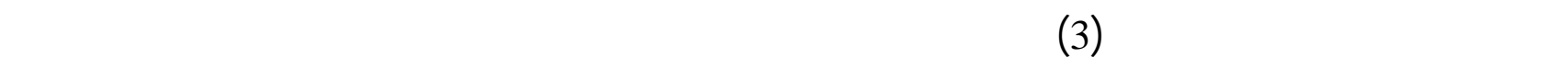
الطاقة (Adsul et al., 2007).

\section{5 - الكثف عن إنتاج المنيبت الهضوبة:}

لقحت قنافي الوسط الزرعي (أ و ب) بالبكتريا المشخصة بالطرق الفياج الكيميلحيوية المنكورة في الفقرة

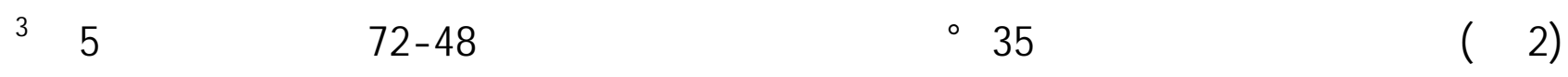

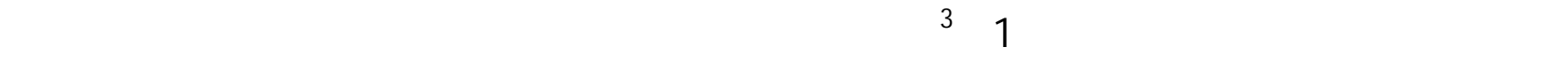
اللون الأخضر دليلا على وجود الكحول في الوسط (Cruickshank et al., 1975).

\section{النتائج و المنالفة}

يوضح الجدول (2) الاختبارات الكيميلحيوية لبكتريا C. cellulovorans مقارنة مع بكتريا

C. cellulolyticum

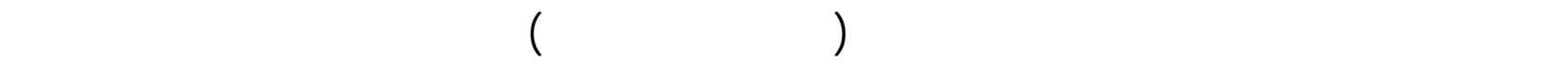

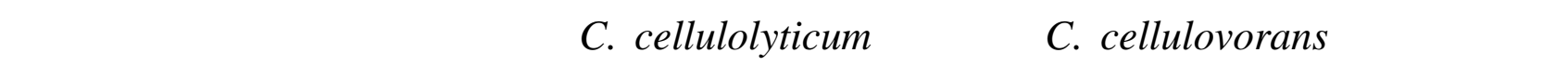

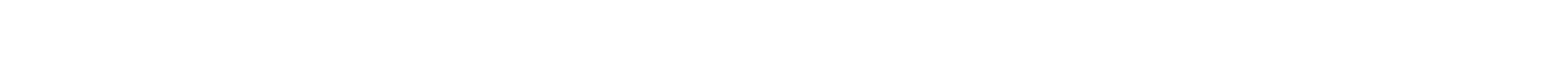

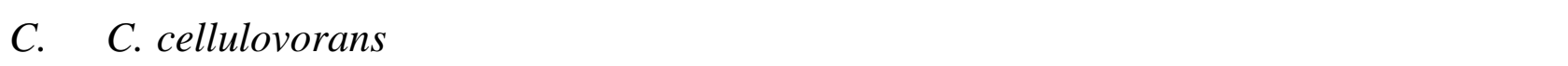
.cellulolyticum

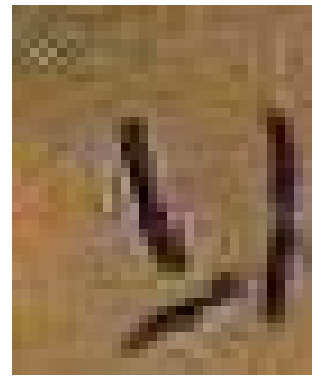

B

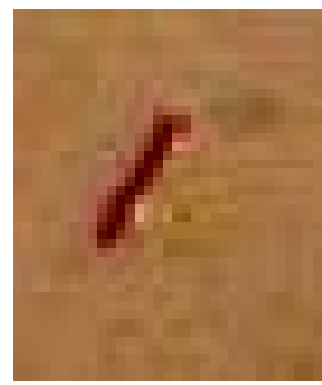

A

(B) C. cellulolyticum الصورة 2: بكتربا C. cellulovorans (A) والبكنربا

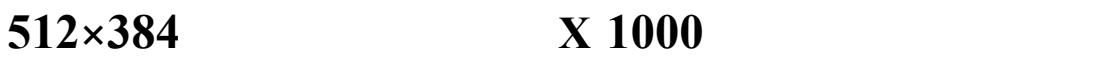


ويبين الجدول (3) نتائج تكون الكحول في الوبط الزرعي بولططة الفعالية التخميرية لبكتريا C. cellulovorans

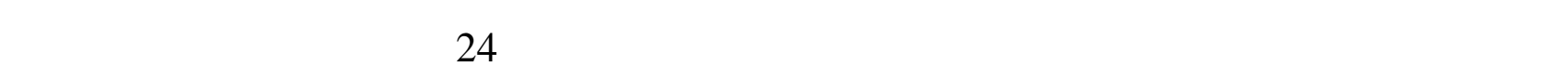

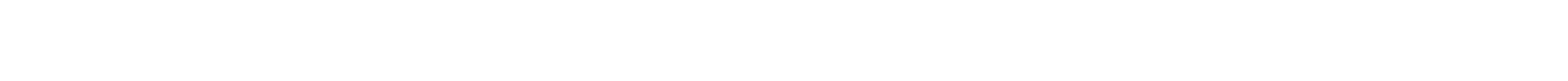

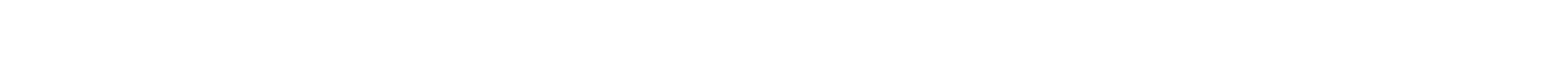
لطول مدة التخمير التي وصلت 96ساعة من بدء التجربة، وقد تكون الفعاليه الانزيمية التي تمتلكها بكتريا C. cellulovorans

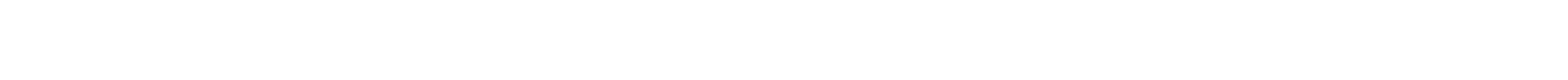
البلحثون (Murashim et al., 2003 ; Matano et al., 1994) ويوضخ الجدول (4) قدرة بكتريا C. cellulolyticum على التتاج الكحول من الانواع المختلة من الاوسطا

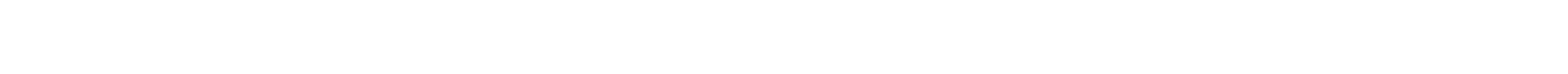

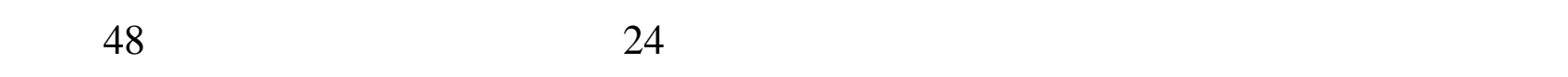

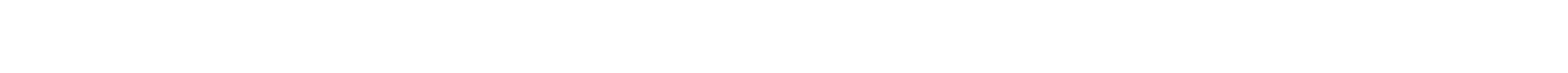

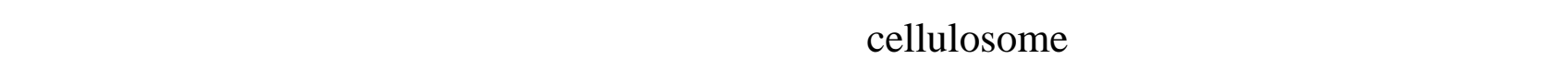
في نسب لشبال للسليلوزات وكما نكر في الجدول (1) وهذا ما لُشار اليه البلحثين في درلساتهيم (Mohand-Oussaid et al., 1999 ; Mitikka et al.,1995) 
C. cellulolyticum C. cellulovorans الجطل 2: الختبارت البليوكيميائية لبكتربا

\begin{tabular}{|c|c|c|}
\hline C. cellulolyticum & C. cellulovorans & لاختبارات البليوكيميائية \\
\hline- & + & زاليلوز \\
\hline+ & + & كلوكوز \\
\hline+ & + & ارابينوز \\
\hline+ & + & رلمينوز \\
\hline+ & + & فركتوز \\
\hline+ & + & كالاكتوز \\
\hline+ & + & مالتوز \\
\hline - & - & رايبوز \\
\hline- & - & ماليبايوز \\
\hline- & - & مليزايتوز \\
\hline+ & - & سليبايوز \\
\hline+ & + & ل ل لكتوز \\
\hline- & - & كليسرول \\
\hline+ & + & نشا \\
\hline+ & + & تمبع الجيلاتين \\
\hline+ & + & تخمر عاصف \\
\hline+ & - & صبغة كرله \\
\hline+ & + & النتاج الغاز \\
\hline
\end{tabular}

C. cellulovorans الجطل 3: النتاج الكحط لبكتربا

\begin{tabular}{|c|c|c|c|c|}
\hline بهد 96ساعة & جهد 72ساعة & جيد 48ساعة & بهد 24ساعة & أنواع الأنشلب \\
\hline+ & - & - & - & 1 - -صنوبر \\
\hline$+1+$ & $+1+$ & + & + & 2 \\
\hline+ & - & - & - & 3 - بلوال \\
\hline$+H$ & + & + & - & 4 \\
\hline+ & - & - & - & 5 -جوز \\
\hline++ & + & + & - & 6 - بندق \\
\hline$+1+$ & + & + & - & 7 - يوكالبتوس \\
\hline+ & - & - & - & 8 - تنوب \\
\hline
\end{tabular}

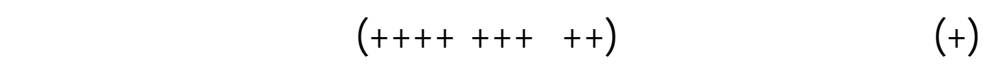


C. cellulolyticum الجطل 4: النتاج الكحط لبكتربا

\begin{tabular}{|c|c|c|c|c|}
\hline بهد 96ساعة & بهد 72تساعة & بهد 48ساعة & جيد 24ساعة & أنواع الأنشلب \\
\hline$+1+$ & + & + & - & 1 - صنوبر \\
\hline $\mathrm{HH}$ & $+H$ & + & + & 2 - زل \\
\hline$+1+$ & + & + & - & 3 - بلوا \\
\hline$+1+$ & $+H$ & + & + & 4 \\
\hline$+H$ & + & + & - & 5 -جوز \\
\hline$+1+1$ & $+1+$ & + & + & 6 - بنوق \\
\hline$+H$ & $H$ & + & - & 7 - يوكالبتوس \\
\hline H+H & $+1+$ & + & + & 8 - تنوب \\
\hline
\end{tabular}

\section{المصادر العربة}

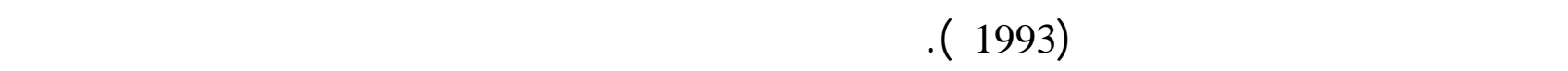
مالطة. رسالة ملجستير، كلية العلو،، جلمعة الموصل.

\section{المصاكر الأجنبية}

Adsul, M.; Jayant, K.; Kulbhushan, B.; Digambar, G. (2007). Production of Lactic Acid from Cellobiose and Cellotriose by Lactobacillus delbrueckii Mutant Uc-3. Appl. Environ. Microbiol. 73 (15), 5055-5057.

Boisset, C.; Armand, S.; Drouillard, S.; Chanzy, H.; Driguez, H.; Henrissat, B. (1998). "Structure-Function Relationships in Cellulases: the Enzymatic Degradation of Insoluble Cellulose." Section of Biochemistry, Molecular and Cell Biology, Cornell University, Ithaca, pp. 124-132.

Cavedonk, L.B.; Canale, A. (1990). Cellulase system of a free-living mesophilic Clostridium (Strain C7). J. Bacter., 172, 4222-4230.

Cruickshank, R.; Duguid, J.P.; Marmion, B.P.; Swan, R.H.A. (1975). "Medical Microbiology". 12th ed., Longman Group Ltd., New York.

Desvaux, M.; Guedon, E.; Petitdemange, H. (2001). Carbon flux distribution and kinetics of cellulose fermentation insteady-state continuous cultures of Clostridium cellulolyticum on a chemically defined medium. J. Bacteriol., 183,119-130.

Diaz-vaz, J.E.; Ananías, R.A.; Rodríguez, S.; Torres, M.; Fernández, A.; Poblete, H. (2009). Compression wood in Pinus radiata II: density and chemical composition. $J$. Maderas. Ciencia y tecnología, 11(2), 139-151.

Doi, R.H.; Kosugi, A. (2004). Cellulosome: plant-cell-wall-degrading enzyme complexes. $J$. Nat. Rev. Microbiol. 2, 541-551.

Doi, R.H.; Park, J.S.; Liu, C.C.; Malburg, L.M.; Tamaru, Y.; Ichi-ishi, A.; Ibrahim, A. (1998). Cellulosome and noncellulosomal cellulase of Clostridium cellulovorans. Extremophiles. J. Nat. Rev. Microbiol. 2, 53-60. 
Fierobe, H.P.; Bayer, E.A.; Tardif, C.; Czjzek, M.; Mechaly, A.; Belaich, A.; Lamed, R.; Shoham, Y.; Belaich, J.P. (2002). Degradation of cellulose substrates by cellulosome chimeras. J. Biol. Chem. 277, 49621-49630.

Hungate, R.E. (1969). "A Roll Tube Method for Cultivation of Strict Anaerobes": In J. R. Norris and D. W. Ribbons (ed.), Methods in microbiology. Vol. 3B. Academic Press, Inc., New York. pp. 117-132.

Giallo, J.; C. Gaudin, J.P.; Belaich, E.P.; Caillet-Mangin, F. (1983). Metabolism of glucose and cellobiose by cellulolytic mesophilic Clostridium sp. strain H10. Appl. Environ. Microbiol. 45, 843-849

Gowen, C.M.; Fong, S.S. (2010). Exploring biodiversity for cellulosic biofuel production. Chem. Biodivers, 7,1086-1097.

Klemn, D.; Heublein, B.; Fink, H.P.; Bohn, A.(2005). Cellulose fascinating biopolymer and sustainable raw material. J. Angew. Chem. Int. 44, 3358-3393.

Koichiro, M.; Akihiko, K.; Roy, H.D. (2002). Determination of subunit composition of Clostridium cellulovorans cellulosomes that degrade plant cell walls. Appl. Environ. Microbiol. 68, 41610-1615.

Matano, Y.; Park, J.S.; Goldstein, M.A.; Doi, R.H. (1994). Cellulose promotes extracellular assembly of Clostridium cellulovorans cellulosomes. J. Bacteriol. 176, 6952-6956.

Mohand-Oussaid, O.; Payot, S.; Guedon, E.; Gelhaye, E.; Youyou, A. (1999). The extracellular xylan degradative system in Clostridium cellulolyticum cultivated on xylan: evidence for cell-free cellulosome production. J. Bacteriol. 181,4035-4040.

Mitikka, M.; Teeaar, R.; Tenkanene, M.; Laine, J.; Vuorinene, T. (1995). "Sorption of Xylans on Cellulose Fibers, in 8th International Symposium on Wood and Pulping Chemistry". Helsinki, Finland. pp. 231-236.

Murashim, K.; Kosugi, A.; Doi, R.H. (2003). Synergistic effects of cellulosomal xylanase and cellulases from Clostridium cellulovorans on plant cell wall degradation. $J$. Bacteriol., 185, 1518-1524.

Prescott, L.M. ; Harley, T.P.; Klein, D.A. (1996). "Microbiology". 3rd ed., WMC. Brown communication, Inc., Lowa, USA., pp. 449-177.

Roger, C.P. (1984)." The Chemical Composition of Wood". U.S. Department of Agriculture, Forest Service, Forest Products Laboratory, Madison, American Chemical Society, pp.54-126

Shoseyovo, S.; Doi, R.H. (1990). Essential 170-kDa subunit fordegradation of crystalline cellulose by Clostridium cellulovorans cellulase. J. Nat. Acad. Scie. 87, 2192-2195.

Shoseyovo, S.; Hamamotto, S.; Foong, F.; Doi, R.H. (1990). Cloning of Clostridium cellulovorans endo- 1,4-beta-gIucanase genes. J. Biochem. Biophy., 169, 667472.

Sleat, R.; Mah, R.A.; Robinsom, R. (1984). Isolation and characterization of an anaerobic, cellulolytic bacterium, Clostridium cellulovorans sp. nov. J. Appl. Environ. Microbiol., 48,88-93.

Sung, O.k.; Han, H.Y.; Cho, H.; Yukawa, M.I.; Roy, H.D. (2004). Regulation of expression of cellulosomes and noncellulosomal (Hemi) Cellulolytic Enzymes in Clostridium cellulovorans during growth on different carbon sources. J. Bacteriol. 186 (13) 4218-4227. 
Vian, B.; Brillouet, J.; Satiat-Jeunemaitre, B. (1983). Ultrastructural visualization of xylans in cell walls of hardwood by means of xylanase-gold complex. J. Biol. Cell. 49,179-182.

Wendy, H.; Yongchao, L.; Yunfeng, Y.; James, C.L. (2011). Metabolic engineering of Clostridium cellulolyticum for production of isobutanol from cellulose. Appl. Environ. Microbiol., 77(8), 2727-2733

Wood, W.A.; Scorr, T.K. (1988). Methods for measuring cellulose activities. J. Enzy., 160, 87-112. 